\title{
Evaluation of Resources of a Part Depending on its Renewal Density
}

\author{
Ivan Masienko ${ }^{1,}$, Sergei Shevchenko ${ }^{1}$, and Artem Vasilenko ${ }^{1}$ \\ ${ }^{1}$ Kuban State Agrarian University named after I.T. Trubilin, the City of Krasnodar, Russia, 350044
}

\begin{abstract}
The article proposes a method to obtain the numerical characteristics of the assessment of the resource of a part on the basis of experimental data on the element renewal density, which can significantly reduce the cost of labor, funds and time to obtain the required results. A methodological approach to the use of experimental data on the renewal density to evaluate the numerical characteristics of the original law of distribution of the resource of an element is presented.
\end{abstract}

The need to replace failed parts of agricultural machinery units is perhaps the main indicator on the basis of which most standards used in planning and managing the technical support of the machine and tractor fleet are calculated. The indicator of the need for the replacement of failed parts directly forms the standards for the need for labor resources and production capacity for technical service, as well as the standard for the need for funds for spare parts and materials. Through such standards, it indirectly influences the formation of one of the main indicators of the machine - costs per unit of work performed.

The latter indicator is the main criterion for optimization in the solution of such problems as optimization of the system of repair and maintenance actions, optimization of the service life of machines and optimization of the strategy for renewing the fleet of vehicles.

In the overwhelming majority of investigations, it is assumed that costs per unit of operating time increase progressively with the age of the machine. Usually, this connection is expressed by the power dependence of the type with the exponent $\mathrm{B}$, greater than one [1]. In fact, this means that the need to replace failed elements is governed by the power dependence with the same exponent, since the costs are obtained by multiplying the number of replacements by the cost of one replacement. This dependence describes the specific need for replacement of a part satisfactorily only in the initial segment of the machine service life.

To assess the need to replace the elements of an old machine operating beyond the terms of the standard service life, such a dependence is unsuitable, since it does not reflect the physical nature of the machine aging processes.

This work is aimed at the development of a method of the prediction of the resource of a part depending on its renewal density.

Such a technique can be created only having the knowledge of the patterns of change in the need to replace a machine part at different periods of its life.

\footnotetext{
* Corresponding author: ivan.masienko@yandex.ru
} 
Knowledge of these patterns makes it possible to predict more reasonably the need for replacement of parts for a fleet of vehicles with any age composition.

The classical method for determining the parameters of the law of distribution of the resource of a part on the basis of experimental data is the processing of the static series of the element time to failure $[2,3]$. The method involves the organization of continuous observations of the operation of machines, registration of the operating time of the machine at the time of the occurrence of a failure and, as a result of such observations, obtaining the static series of the element time to failure. The processing of such static series by standard or original methods allows determining numerical characteristics and parameters of the element resource distribution law $[4,5]$.

The advantage of this method is high accuracy and reliability of the estimates of the distribution parameters with a sufficient number of observations. The method makes it possible with great probability both to choose the type of the distribution law and to obtain estimates of its parameters. However, it also has significant drawbacks. The complexity of collecting information and the required observation time are too high, especially in the case of parts with large resources, when a failure sometimes has to be expected for several years. Therefore, this method is mainly used for expensive parts.

An alternative method is to use the renewal density of a part. If the researcher has available experimental data about the element renewal process, then on its basis it is possible to estimate the numerical characteristics of the law of distribution of the resource of the element and, ultimately, the parameters of this law, if its form is known. It is possible to obtain data about the renewal process at a much lower cost than data on time to failure. To do this, it is sufficient to group the machines by age (or the accumulated operating time since the machine was put into operation) and to select the number of element replacements per year for each group. Dividing this number by the total annual operating time of machines in the group, it is possible to obtain the element renewal density for the corresponding age. By combining such data for all age groups, the entire renewal density curve can be plotted.

With this approach, it is not required to have the operating time of the machine at the time of failure. This is very important, since the time to failure under ordinary operating conditions is not registered as a rule. Therefore, with this approach, there is no need to organize special observations of the machine.

Using an example with specific numerical data, a possible methodological approach to the use of experimental data on the renewal density to assess the numerical characteristics of the original law of the element resource distribution is presented.

Let us assume that there are experimental data on the element renewal density (Table 1). It is known that for this element the resource usage coefficient $k_{\text {ир }}$ makes 1 , the resource renewal indicator $q$ makes 0.8 . It is also known that the resource of a given element is distributed according to the normal law with the coefficient of variation $v=0.4$.

It is required to determine the estimate $m$ of the mathematical expectation of the resource of the element.

Table 1. Element renewal density

\begin{tabular}{|c|c|c|c|c|c|c|c|}
\hline $\begin{array}{c}\text { Operating } \\
\text { time, } \\
\text { thousand } \\
\text { moto hours }\end{array}$ & $\begin{array}{c}\text { Renewal } \\
\text { density, } \\
\text { 1/thousand } \\
\text { moto hours }\end{array}$ & $\begin{array}{c}\text { Operating } \\
\text { time, } \\
\text { thousand } \\
\text { moto hours }\end{array}$ & $\begin{array}{c}\text { Renewal } \\
\text { density, } \\
1 / \text { thousand } \\
\text { moto hours }\end{array}$ & $\begin{array}{c}\text { Operating } \\
\text { time, } \\
\text { thousand } \\
\text { moto hours }\end{array}$ & $\begin{array}{c}\text { Renewal } \\
\text { density, } \\
1 / \text { thousand } \\
\text { moto hours }\end{array}$ & $\begin{array}{c}\text { Operating } \\
\text { time, } \\
\text { thousand } \\
\text { moto hours }\end{array}$ & $\begin{array}{c}\text { Renewal } \\
\text { density, } \\
\text { 1/thousand } \\
\text { moto hours }\end{array}$ \\
\hline 1 & 0.016 & 5 & 0.143 & 9 & 0.200 & 13 & 0.181 \\
\hline 2 & 0.036 & 6 & 0.173 & 10 & 0.191 & 14 & 0.185 \\
\hline 3 & 0.066 & 7 & 0.197 & 11 & 0.182 & 15 & 0.185 \\
\hline 4 & 0.101 & 8 & 0.202 & 12 & 0.182 & 16 & 0.188 \\
\hline
\end{tabular}


A graphical representation of the data from Table 1 is shown in Figure 1. A rough estimate of the mathematical expectation can be obtained if we use the stationarity property [6] of the renewal process.
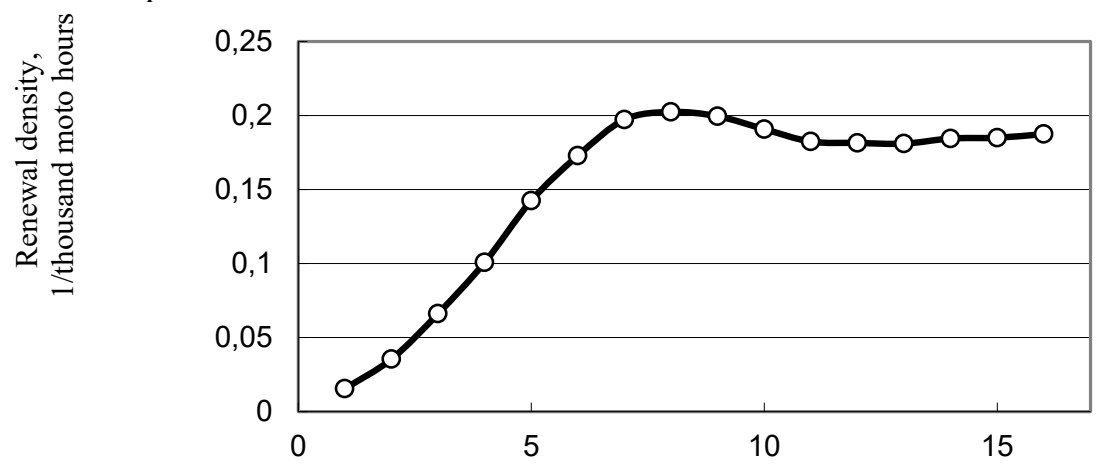

Accumulated operating time, thousand moto hours

Fig. 1. Renewal density

The core of this property is that with unlimited increase in the accumulated operating time $t$, the density $h$ tends to its stationary value $h=1 / T_{\mathrm{cp}}$, where $T_{\mathrm{cp}}$ - mathematical expectation of the resource of the element. Since at the end of the machine service life, all primary parts will be replaced by secondary ones with different average resource, the resulting value should be corrected by dividing by $q$ and $k_{\text {ир }}$. Thus, the value $[7,8,9]$ can be taken as the first approximation for the mathematical expectation of the primary resource of an element.

$$
m_{1}=\frac{1}{h_{\text {пред }} q k_{\text {вр }}},
$$

where $m_{1}$ - first approximation for the mathematical expectation of resource, thousand moto hours;

$h_{\text {пред }}-$ extreme renewal density, 1 /thousand moto hours;

$q$-resource renewal indicator;

$k_{\text {up }}$ - resource usage coefficient.

For the example under consideration, the extreme density can be taken equal to 0.18 1/thousand moto hours (Figure 1). Thus, the first approximation is as follows:

$$
m_{1}=\frac{1}{0,18 \cdot 0,8 \cdot 1} \approx 7 \text { thousand moto hours }
$$

Using the simulation model described above, the renewal density for this value of the mathematical expectation of the resource is calculated and a graph combined with the graph of the experimental data is constructed (Figure 2). 


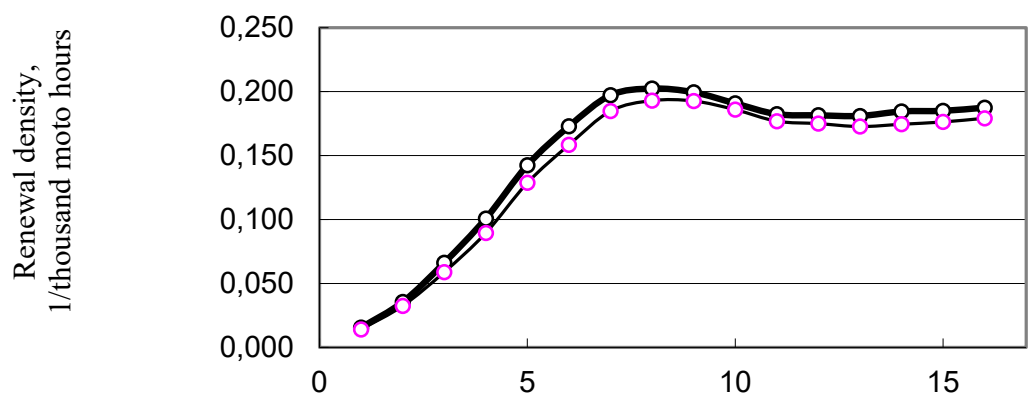

Accumulated operating time, thousand moto hours

The upper curve represents experimental data, the lower one - first approximation.

Fig. 2. Renewal density

As it can be seen from the graph, the found renewal density curve is below the experimental data. This indicates that the estimate of the average resource we have adopted is overestimated (the intensity of the error flow with this estimate is less than that one observed experimentally).

As the second approximation, the value reduced in comparison with the first estimate, for instance, $m_{2}=6.0$ thousand moto hours, is taken. After the calculation of the renewal densities for it and the construction of a graph (Figure 3), it is possible to find that the density curve passes above the experimental data, that is, our second estimate is underestimated. Thus, the true value of the mathematical expectation is between the first and second approximations. After the performance of several more iterations of the same type, the mathematical expectation of the element resource is found to make 6.7 thousand moto hours. In this case, the graph of the renewal density coincides thoroughly with the experimental data.

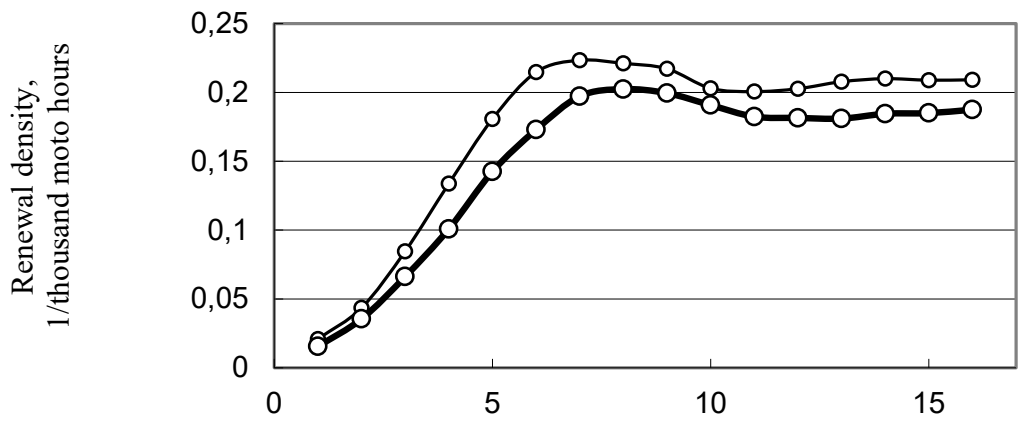

Accumulated operating time, thousand moto hours

The upper curve represents the second approximation, the lower one - experimental data.

Fig. 3. Renewal density

In the considered example, the mathematical expectation of the resource of an element is found under the assumption that the coefficient of variation is known. The described method is also applicable in the case when the coefficient of variation is unknown. In this 
case, it is necessary to scan cyclically the values of the coefficient of variation in the range of its possible values (for tractor elements, this is the range 0.2-0.5).

At each turn of this cycle, for the next fixed value of the coefficient of variation, it is necessary to find the best estimate of the mathematical expectation of the resource using the above algorithm and to compare the obtained renewal densities with experimental data. As the final estimate for the coefficient of variation, one of the examined values of $v_{i}$ is taken, which provides the smallest discrepancy between the renewal densities and the experimental data, and as the mathematical expectation of the resource, the estimate corresponding to this value $m_{i}$ is taken. In this case, the sum of the squares of the deviations of the calculated values from the experimental ones can be used as a measure of the density discrepancy.

The coefficient of variation has a very weak effect on the value of the mathematical expectation, therefore, in many cases, without much damage to the accuracy of the estimates obtained for the coefficient of variation, it is possible to take a certain average value from the interval $0.3-0.35$ and consider it as given.

Thus, the proposed method to obtain the numerical characteristics of the resource distribution of an element on the basis of experimental data on the element renewal density can significantly reduce labor costs, funds and time to obtain the required results.

\section{References}

1. E. Yudina, Hydraulic Control Valve Spool Restoration by Composite Galvanic Coating, E. Yudina, M. Kadyrov, A. Serguntsov, E. Samurganov, In the Collection: IOP Conference Series: Materials Science and Engineering. International Conference on Mechanical Engineering, Automation and Control Systems 2020, MEACS 2020, P. 012044, (2021)

2. M. Yudin, Experiment Planning and Processing of its Results, Krasnodar: Krasnodar State Agrarian University, 239 p., (2004)

3. A. Selivanov, Theoretical Foundations of Repair and Reliability of Agricultural Machinery, M., Kolos, 248 p, (1978)

4. I. Masienko, Theoretical Determination of the Harvester Propulsion Type for Rice Harvesting, I. Masienko, I. Grigoryan, S. Shevchenko, In the Collection: IOP Conference Series: Earth and Environmental Science, 403(1), P. 012100, (2019)

5. I. Masienko, Patent Analysis of Design Features of Non-Cereal Crop Choppers, I. Masienko, A. Vasilenko, S. Schvchenko, E3S Web of Conferences, 193, P. 01029, (2020)

6. V. Konovalov, Analytical Study of Disk Harrows Grinding Unit Design Parameters, V. Konovalov, S. Konovalov, V. Igumnova, IOP Conference Series: Earth and Environmental Science, 403, P. 012086, (2019)

7. V. Konovalov, Justification of Design Parameters of Disk Working Body with Changing Radius of Curvature, V. Konovalov, E3S Web of Conferences, 193, P. 01014, (2020)

8. V. Konovalov, Constructive-Technological Diagram of Rotary-String Cultivator and Definition of its Main Parameters, V. Konovalov, S. Konovalov, V. Igumnova, E3S Web of Conferences, 126, P. 00039, (2019)

9. I. Masienko, Development Prospects of Mobile Rice Straw Crushers, In the Collection: E3S Web of Conferences, 126, P. 00022, (2019) 